\title{
Evaluation of International Technology Transfer for Climate Change Action in Sabah, Malaysia
}

\author{
Daisy Aloysius ${ }^{1}$, Mohd.Yusrie Abdullah ${ }^{1}$, Nurfaeziane Nordin ${ }^{1}$, Ailen Ganing ${ }^{2}$, Jiro \\ Iguchi $^{3}$ \\ ${ }^{1}$ Environment Protection Department, Malaysia \\ ${ }^{2}$ Ditto \\ ${ }^{3}$ Conference of Earth Environment from Akita, Japan
}

\begin{abstract}
National Policy on Climate Change of Malaysia stipulates increase of awareness and community participation as one of its strategic thrusts toward which national responses on climate change in all sectors will be directed. Sabah state is the first state in Malaysia to formulate a statelevel environmental education policy. In addition, the state is the only state in Malaysia that established a cohesive network of stakeholders concerning environmental education. However, the environmental education in the state had focused on conservation of the biodiversity conservation, etc, and there had been little effort to raise public awareness on climate change and countermeasures against it, such as energy saving measures. On the other hand, in Japan, they have an effective institution at the local administration level for promoting global warming countermeasures, such as the prefectural promotion centres for climate change action, the climate change action officers, etc., which are stipulated in their legal system. Thus, an international collaboration project for three years was planned and implemented to establish a state Centre for Climate Change Action in Sabah, with technical assistance from Japan. With financial assistance from the Environmental Restoration and Conservation Agency (ERCA) of Japan, the Environment Protection Department Sabah (EPD) implemented the project, with technical assistance form he Conference of Earth Environment from Akita (CEEA), an Environmental NGO based in Akita, Japan. This paper evaluates the project, applying the Project Cycle Management (PCM) method, and the DAC five evaluation criteria. Among the five criteria, the Effectiveness of the project was evaluated as extremely high, as the Centre conducted awareness programmes 159 times with 15,728 participants in total, which is far beyond the planned indicators set to verify achievement of the Project Purpose. The Relevance and the Efficiency of the project were evaluated as high, and for the Impacts, the project has exerted some positive impacts. However the Sustainability of the Project is uncertain, as the capacity of the Centre at EPD to maintain and develop the awareness activities even after the project has not been confirmed yet from the institutional, technical and financial points of view.
\end{abstract}

Keywords: Collaboration, climate change, awareness, programme

\section{Introduction}

\section{National Context}

National Policy on Climate Change of Malaysia states increase of awareness and community participation as one of its strategic thrusts toward which national responses on climate change in all sectors will be directed as shown below:

"ST9-P4: Increase awareness and community participation to promote behavioural responses to climate change." (Ministry of Natural Resources and Environment Malaysia, 2009)

The key actions for each of the strategic thrust also defines types of education and awareness and their targets for raising awareness on climate change as shown below: 
"KA38-ST9 Adopt systematic and targeted formal and informal education and awareness raising on climate change through the following approaches:

- Involvement of various stakeholders including non-government organisations (NGOs), community based organisations (CBOs) and the media;

- Enhance cooperation between government and private sectors including corporate responsibility; and

- Targeting special groups. “(ibid.)

In addition, the Key Actions also include strengthening of networks at the state and local government levels.

"KA37 - ST8: Strengthen collaborative networks and capacity of agencies at the federal, state and local government levels." (ibid.)

To make the Thrust and implement the Key Actions above in Malaysia, an effective institution is required at the state and local levels to promote awareness of the current status of the global warming and the importance of global warming countermeasures.

\section{State Context}

The Sabah State in Malaysia is endowed with rich natural resources, beautiful tropical landscapes, and pristine environment. These natural assets are crucial backbone for the State's development. Protection and conversation of natural resources and the environment continue to be pursued with the target to increase totally protected area (TPA) in Sabah to thirty (30) percent in 2025. Currently, the totally protected areas (TPAs) in Sabah is 26 percent of Sabah's land area.

Sabah state is the first state in Malaysia to formulate an environmental education policy, named Sabah Environmental Education Policy (SEEP) in 2009 (Ministry of Tourism, Culture and Environment Sabah, 2009). In addition, the state is the only state in Malaysia that established a cohesive network of stakeholders concerning environmental education, which is called the Sabah Environmental Education Network (SEEN) in 2005 (Hassan, et al., 2009). SEEN membership has increased from 22 members in 2005 to 42 members to date. The Environment Protection Department (EPD), Sabah is the secretariat for SEEN overseeing implementation of SEEP.

According to studies on status of environmental education in Sabah (Ajam and Iguchi, 2002, EPD, 2014), in Sabah they were active in promoting environmental education focusing on conservation of the terrestrial natural ecosystems (forest management), biodiversity conservation, marine biodiversity conservation, water pollution control, water resource management and waste management.

However, there had been little effort to raise public awareness in the state on the climate change and measures against it such, as energy saving measures. Hence, this project was seen as a good opportunity to promote public awareness about the global climate change in the state. 


\section{Experience in Japan}

In Japan, they have an effective institution at the local administration level for promotion of global warming countermeasures, such as prefectural promotion centres for climate change action, climate change action officers, etc. stipulated in Act of Promotion of Global Warming Countermeasures of 1998 (revised in 2002, 2005, 2006, 2008, 2013, 2016).

In Japan, prefectural governors and mayors of designated cities, etc. may designate an organization as a regional centre for climate change action in a prefecture or a designated city. The regional centres for climate change action shall perform operations within their region such as conducting education and public awareness activities concerning the current status of the global warming and the importance of global warming countermeasures, and supporting the activities of climate change action officers and private organizations engaged in activities to promote global warming countermeasures, etc.

Prefectural governors and mayors of designated cities, etc. may also delegate persons to serve as climate change action officers who are enthusiastic and knowledgeable concerning the promotion of activities for the regional dissemination of knowledge regarding the current situation of global warming and related countermeasures and for the promotion of global warming countermeasures.

The Japan Center for Climate Change Action (JCCCA) is a national centre designated by Minister of Environment, which conduct liaison and coordination regarding the operations of the regional centres for climate change action, providing training for persons engaged therein, and providing guidance and other assistance to the regional centres for climate change action.

An international collaboration project was planned and implemented to establish a state Centre for Climate Change Action in Sabah, Malaysia with technical assistance from Japan, referring to the experience of the above regional centres and other institutions for climate change countermeasures.

This paper evaluates the process and achievement of the project, to judge achievement of the project and its contribution to the above common goals at national level and global levels. The Monitoring and Evaluation of the Project Cycle Management (PCM) Method (FASID 2016) is applied for the evaluation. Following the PCM method, the five evaluation criteria which were proposed by the Development Assistance Committee (DAC) of the Organization for Economic Cooperation and Development (OECD) are applied as basis for evaluation.

After the five evaluation criteria were applied respectively, the overall conclusions are drawn based on the results, to answer the main questions if the project has achieved its objectives and if it has contributed to the common national/global goals to change awareness, behaviour and actions of the people toward prevention of the global climate change. Then based on the evaluation results, discussion on future direction of the project is presented. 


\section{Project Design}

\section{Minutes of Understanding and Project Framework}

The state government of Sabah, Malaysia established an international collaboration with the Conference of Earth Environment from Akita (CEEA), an Environmental NGO based in Akita, Japan, for three years to increase awareness and change behaviour towards the prevention of global warming in Sabah, Malaysia. The memorandum of understanding (MOU) for this project was signed between the Ministry of Tourism, Culture and Environment, Sabah (MTCE) with CEEA on 24 Mar. 2017.

The project design of the three years collaboration was described in the format of the Project Design Matrix (PDM) following the Project Cycle Management (PCM) Method (FASID 2008, FASID 2016) and attached to the MOU. The PDM state the project Name as "Establishment of a Centre for Climate Change Actions in Sabah," the project area as Sabah state, Malaysia, the Target Group as the household sector in Sabah, and the project duration as April 2016 to March 2019.

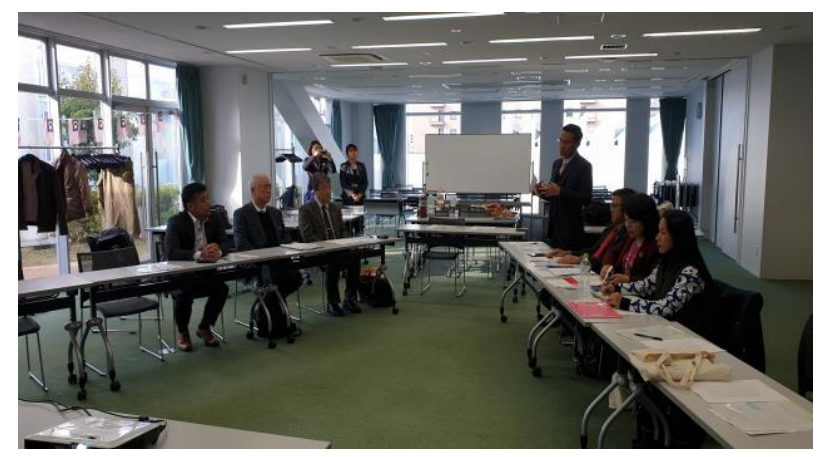

Picture 1: Meeting for monitoring of the project between CEEA and EPD held in Akita City.

\section{Project Objectives}

According to the PDM, the "Project Purpose" (an objective to be achieved by the Project before the end of project period) is stipulated as follows:

"The Centre for Climate Change Actions in Sabah functions as the similar centres in Japan."

The above Project Purpose is planned to be achieved by three "Outputs" (intermediate objective to be attained through Activities as a step toward the achievement of the Project Purpose), such as:

"Output 1: Environment Protection Department (EPD) as the Centre for Climate Change Actions in Sabah is established and its capacity is enhanced."

"Output 2: Awareness activities to prevent global warming are implemented throughout Sabah."

"Output 3: Behaviour change of the target citizens is observed as a result of the activities by the Centre."

There are two "Overall Goals" (objectives to be achieved after the project as a result of the project) expected as follows: 
"Change of awareness and behaviour toward prevention of global warming is accelerated in the household sector including education in Sabah, Malaysia."

"The Centre for Climate Change Actions in Sabah is known in the whole Malaysia."

\section{Activities and Inputs}

To produce the above Output to achieve the project Purpose, various activities were planned and implemented. Major activities were summarized as follows:

- Organize annual seminars in Kota Kinabalu inviting the officers of EPD and affiliated members of SEEN (Sabah Environmental Education Network), such as science teachers, environment NGO, etc.

- Conduct training courses in Japan (once a year).

- Conduct surveys of citizen's awareness about climate change (baseline survey and post activity survey).

- Assign human resource and allocate a desk and other equipment to make the Centre functions in Environment Protection Department by March 2017.

- Develop awareness materials and tools based on the knowledge mastered in the training courses in Japan.

- Distribute and use the awareness materials and tools at schools and the local government agencies.

- Publish the establishment of the Centre through leaflets, posters, website, newspaper and/or administrative public relations magazine.

To implement the above activities, inputs including the below items were mobilized from the both Japanese and Sabah sides. The cost of the inputs from the Japanese side was born by financial assistance from the Japan fund for Global Environment under Environment Restoration and Conservation Agency (ERCA) in Japan:

(Japanese side)

- CEEA members for coordination of the project.

- Dispatch of Japanese Experts in awareness as lectures of the climate change actions in Sabah.

- Training by the Japanese experts in Sabah for officers of state government agencies including EPD and the members of SEEN (Sabah Environmental Education Network), such as science teachers, environment NGO, etc. 
- Training course in Japan for officers/members of state agencies, NGOs, etc. related to climate change countermeasures, including visit to the regional centres for climate change action, JCCCA, etc.

(Sabah side)

- Resources (a desk and human resources) of EPD for the function of the state Centre for Climate Change Actions in Sabah.

- Appointed trainees for the training course.

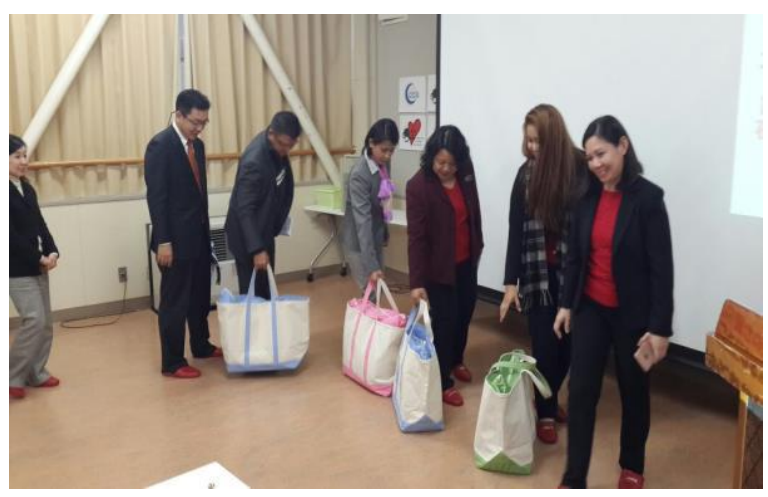

Picture 2: Officials from Sabah having a training on usage of hands-on material (the bags to understand energy consumptions by their weights) in Japan in 2017.

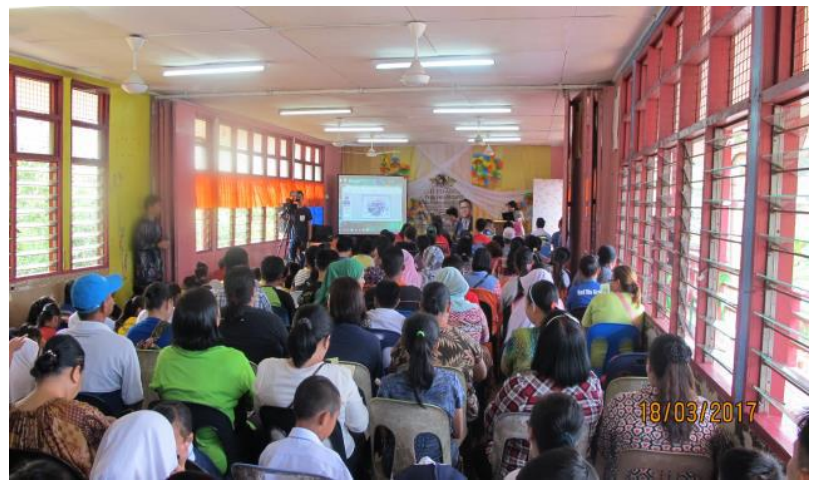

Picture 3: Awareness activity for students and parents in a primary school in Sabah implemented by EPD officials in 2017.

\section{Results}

The Project was completed in 24th March 2019 as stipulated in the MOU. The evaluations of the project applying each of the five criteria are as follows:

\section{Relevance}

The Relevance is evaluated as high for the following reasons. As stated above, the objectives of the project are in line with the strategic thrust and key actions in the Malaysia's National Policy on Climate Change which was launched on $30^{\text {th }}$ August 2010. 
The Japan has an institution stipulated in their law in 1998 for education and public awareness activities concerning the current status of the global warming and the importance of global warming countermeasures. It consists of the regional centre for climate change action, climate change action officers, and the Japan Center for Climate Change Action (JCCCA), etc. These institutional settings and their technology, knowledge and experience in the education and awareness should be useful reference for Sabah to establish their effective institution to achieve the strategic thrust and key actions in the Malaysia's National Policy on Climate Change.

EPD and other concerning state government agencies of Sabah discussed before signing the MOU $\mathrm{f}$ the project if countermeasures to the global climate change would fall in the jurisdiction of the federal government of Malaysia or the state government of Sabah. It was decided that enhancing awareness of the current status of the global warming and the importance of global warming countermeasures could be within the state jurisdiction.

\section{Effectiveness}

It can be said that the above Project Purpose has been achieved. At the beginning of the project, EPD officially established the Centre in their office and assigned their officer in charge. Since then the Centre has developed its functions similar to the regional centre in Japan, producing the following outcomes:

The Centre at EPD with partners namely Department of Environment Sabah, Kota Kinabalu Wetland, Taman Tun Fuad Secondary School, etc. has conducted awareness programmes far more than the target figures planned in the PDM (several times in Japanese Fiscal Year 2016, and 10 times per following year). Within a period of 109 weeks starting from February 2017 to March 2019, the Centre conducted awareness programmes 159 times with 15,728 participants in total (Table 1). The highest number of participants in the programmes was students accounting $73 \%$ of the participants, followed by community members (12\%), teachers $(11 \%)$ and parents at (4\%) as shown in Table 2 :

Table 1 Number of awareness programmes applying the outputs of the project

\begin{tabular}{|c|c|c|c|c|}
\hline & $\begin{array}{c}13 \text { Feb.- } 31 \text { Dec. } \\
2017\end{array}$ & $\begin{array}{c}1 \text { Jan.- } 31 \text { Dec., } \\
2018\end{array}$ & $\begin{array}{c}1 \text { Jan- } 22 \text { Mar. } \\
2019\end{array}$ & Total \\
\hline Number of Programme & 95 & 54 & 4 & 153 \\
\hline Locations & 35 & 50 & 4 & 54 \\
\hline $\begin{array}{l}\text { Number of Participants } \\
\text { in the programme }\end{array}$ & 7,640 & 7,442 & 646 & 15,728 \\
\hline
\end{tabular}

Table 2 Number of participants in the programmes and their occupations

\begin{tabular}{|l|r|r|r|r|}
\hline & \multicolumn{1}{|c|}{ Students } & \multicolumn{1}{c|}{ Teachers } & Communities & \multicolumn{1}{c|}{ Parents } \\
\hline Number of participants & 11,492 & 1,690 & 1,867 & 679 \\
\hline Percentage (\%) & 73.07 & 10.75 & 11.87 & 4.32 \\
\hline
\end{tabular}

- The Centre at EPD has also extended the awareness programme to the neighbouring State of Sarawak in 2017. 
- The Centre at EPD developed some sets of slides and hands-on educational materials including paper boxes to learn the food chain, bags to understand energy consumption, based on what their officers learnt in their training courses in Japan.

- EPD presented the outcome of the project at the Third International Conference on Climate Change 2019 (ICCC2019) in Kuala Lumpur organized by Universiti Putra Malaysia, University of Hacettepe, Turkey and International Institutie of Knowledge Management, Sri Lanka.

For these reasons, it can be concluded that the Effectiveness of the project was extremely high.

\section{Efficiency}

The Efficiency was evaluated from the viewpoint of whether the project had been efficient and whether the procedures adopted had been effective. The Efficiency was evaluated as high, as a result of the appropriateness of the participants in the seminars in Sabah, and training courses in Japan and by active utilization of what the participants learnt in the seminar and training courses. The input of the international experts was fewer compared to a similar project for environmental conservation in Sabah.

The training courses in Japan were conducted annually, three times in total. The organisations in Sabah which dispatched their participants in the training courses are as follows:

1. Ministry of Tourism, Culture and Environment, Sabah: 1 officer, namely the Assistant Minister Tuan Assaffal P. Alian),

2. Environment Protection Department, Sabah: 5 officers including their Director,

3. Attorney General Department of Sabah: 1 officer,

4. Department of Environment (federal government agency) in Sabah: 1 officer,

5. Taman Tun Fuad Secondary School, Sabah: 1 teacher, and

6. Sabah Wetland Conservation Society (NGO managing Kota Kinabalu Wetland Ramsar Site): 1 officer. 


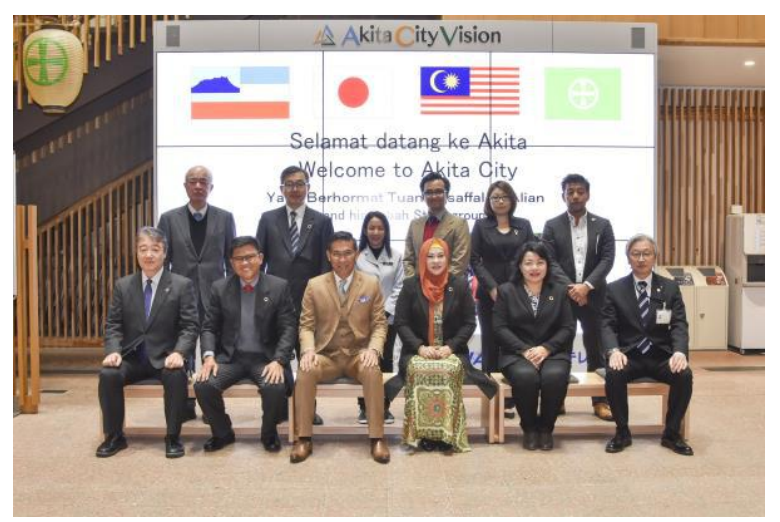

Picture 4: The participants of the third training course in Japan in December 2018, such as Assistant Minister to Ministry of Tourism Culture and Environment Sabah, Director of EPD and senior officials of EPD

Three seminars were organised in hotels in Kota Kinabalu and by the members from SEEN (Sabah Environmental Education Network), such as state government agencies, schools, higher learning institutes, private sector and NGOs.

\section{Impacts}

The evaluation result concluded that the project has exerted some positive impacts and little negative impacts. The Overall Goals of the project stated above which are considered as the planned positive impacts, are expected to be realized after the project ends.

The first Overall Goal, "Change of awareness and behaviour toward prevention of global warming is accelerated in the household sector including education in Sabah, Malaysia." is somehow observed even at this stage. Reaction of the participants and questionnaire survey results in the awareness programmes implemented by the Centre at EPD indicated significant changes in knowledge and awareness of the participants of the programme. However, changes of their behaviours and actions, and extension of such changes to the mass of the population in Sabah have not yet been observed, partly due to the limitation of our survey methods.

The second Overall Goal is "The Centre for Climate Change Actions in Sabah is known in the whole Malaysia." This Goal has not been observed objectively yet, while we can report some facts toward this direction.

For example, just after coming back from the training course in Japan in Dec. 2018, the Assistant Minister of Tourism, Culture and Environment, Sabah, who is one of the participants in the course, chaired a meeting with the electricity provider in Sabah, Sabah Electricity Sdn Bhd (SESB) to enhance awareness on energy saving in Sabah, on 30 January 2019. EPD is currently in the process of formulating an MOU with SESB to enhance energy saving programme as global warming countermeasure in Sabah.

\section{Sustainability}

Sustainability of the project is uncertain. Though the project produced overwhelming results including change of knowledge and awareness of more than 15,000 people in Sabah as stated above, 
the capacity of the Centre at EPD to maintain and develop such activities even after the project has not been confirmed yet, from the institutional, technical and financial points of view.

Technically, the Centre still needs to develop their capacity. For example, they need a scientific method to monitor its contribution to prevent the global warming. The regional centres for climate change action in Japan have an established methodology to estimate amount of reduced carbon emission achieved by changes of actions of citizens after awareness activities. However, to apply the methodology in Sabah, they need to localise the coefficients, etc. in the formula, according to the natural, economic and social conditions in Sabah different from those in Japan.

Moreover, from the institutional point of view, the Centre is unstable. The Centre was just recently established by the project and is currently operated based only on the internal order of EPD, while the regional centres in Japan are established based on the national law. Accordingly, the Centre at EPD does not have particular financial allocation for their operation from the state or federal government.

\section{Discussion}

As a conclusion, the project has made positive impacts to the government and the society in Sabah. EPD as the Centre for climate change action in Sabah will continue to organise and tap various opportunities for awareness raising concerning the global climate change and change of behaviour of the citizens.

In technical aspect, the entre needs an accountable and scientific method to estimate its contribution to reduction of carbon by changes of behaviour of the public. Thus, further study is required to localize the methodology established in Japan to estimate amount of carbon reduced by awareness activities.

To discuss appropriate laws and regulations, and other institutional measures to enhance the Impacts and Sustainability of the awareness for climate change actions, further study is required, such as comparative study of laws and regulations and their enforcement for the awareness in Sabah, Japan, Malaysia, etc.

EPD with the support from the Ministry of Tourism, Culture and Environment Sabah will also continue to extend climate change awareness programme to other target groups, such as the private sector in Sabah, etc. EPD will collaborate with experts of the global climate change and develop more awareness tools. EPD is planning to organise an international climate change conference with the title "First Climate Insight in Sabah: Strengthening Resilience and Diversity in an Era of Global Environmental Change" in the end of October 2019. It is EPD's expectation that CEEA continues to support the State of Sabah in enhancing behaviour change and awareness on climate change in Sabah.

\section{Acknowledgements}

The authors are grateful to the Conference of Earth Environment from Akita (CEEA) for their overall technical assistance in planning, implementation and evaluation of the project. We are also grateful to Environment Restoration and Conservation Agency (ERCA), Japan for their financial assistance to the project. We would like to thank the Japan Center for Climate Change Actions (JCCCA), Tokyo 
and Environment Division, Akita City Hall who dispatched their experts to Sabah and accepted trainees from Sabah for the training courses in Japan.

\section{References}

Ajam, Moktar and Jiro Iguchi (Eds). 2003. Environmental public awareness campaigns in Sabah: case studies, 2002. Kota Kinabalu, Public Awareness Component, Bornean Biodiversity and Ecosystem Conservation (BBEC) Program in Sabah.

EPD, 2014. A study on the Second Monitoring of Sabah Environmental Education Policy Sabah, unpublished.

FASID. 2008. Management Tool for Development Assistance: Participatory Assistance (7th edition).

FASID. 2016. Management Tool for Development Assistance: Monitoring and Evaluation (6th edition).

Hassan, A., Osman, K and Pudin, S. 2009. The Adults Non-Formal Environmental Education: A Scenario in Sabah, Malaysia. Procedia Social and Behavioral Sciences 1(1), pp. 2306-2311

Ministry of Natural Resources and Environment Malaysia. 2009. National Policy on Climate Change.

Ministry of Internal Affairs and Communications, Japan. 2016. Act on Promotion of Global Warming Countermeasures (in Japanese) Date of access: 31 Mar. 2019. http://elaws.egov.go.jp/search/elawsSearch/elaws_search/lsg0500/detail?lawId=410AC0000000117\#G

Ministry of Tourism, Culture and Environment Sabah. 2009. Sabah Environmental Education Policy.

Ministry of Justice, Japan. 2009. Act on Promotion of Global Warming Countermeasures. Date of access: 31 Mar. 2019. http://www.japaneselawtranslation.go.jp/law/detail/?id=97\&vm=04\&re=01 